\title{
IMPACTO DO CUIDADO PARA O DESENVOLVIMENTO SAUDÁVEL DA CRIANÇA NA PRIMEIRA INFÂNCIA
}

\author{
Maria Alice Coelho Ribas ${ }^{1}$ \\ (1) https://orcid.gov/0000-0001-8019-1350 \\ Carmen Rosane Segatto e Souza \\ (1) http://orcid.org/0000-0002-0122-4095
}

Resumo: 0 presente artigo tem por objetivo compreender o impacto que o cuidado dispensado à criança na primeira infância tem sobre o seu desenvolvimento, bem como apresentar o importante papel que a idealização e a reidealização têm no que tange ao cuidado necessário com a criança para o seu desenvolvimento saudável. Foi realizado mediante uma abordagem qualitativa de revisão de literatura narrativa. Para tanto, foi feita uma análise de aspectos apontados pela literatura como relevantes para o entendimento do processo de idealização e reidealização da criança real pelos pais, segundo Franco $(2015,2016)$, Jerusalinsky $(2006,2010)$, Winnicot $(2005,2012)$, Bowlby $(2002)$ e outros autores que tratam do tema. Conclui-se que a capacidade dos pais de idealização e reidealização do filho real é importante para a criação e o fortalecimento dos vínculos parentais considerados imprescindíveis ao cuidado e desenvolvimento saudável da criança.

Palavras-chave: Criança. Desenvolvimento. Idealização. Reidealização.

\footnotetext{
1 Mestre em Filosofia pela Universidade Federal de Santa Maria -UFSM. Professora de Filosofia da Universidade Franciscana-UFN. E-mail: marialicecr@hotmail.com

2 Doutora em Educação pelo Programa de Pós-Graduação em Educação da Universidade Federal de Santa MariaUFSM. Integrante do Grupo de Pesquisa em Educação, Saúde e Inclusão (GEPEDUSI/UFSM). E-mail: carmenrssouza@gmail.com
} 


\title{
IMPACT OF CARE FOR THE HEALTHY DEVELOPMENT OF CHILDREN IN EARLY CHILDHOOD
}

\begin{abstract}
The aim of this article is to understand the impact of early childhood care on the child's development, as well as presenting the important role that the idealization and the reidealização has in what concerns the necessary care with the child for its healthy development. It was performed through a qualitative approach of narrative literature review. To this end, an analysis of aspects pointed out by the literature as relevant to the understanding of the idealization and reidealization process of the real child by the parents was made, according to Franco $(2015,2016)$, Jerusalinsky $(2006,2010)$, Winnicot(2005, 2012), Bowlby (2002) and other authors dealing with the subject. It is concluded that the parents' capacity for idealization and reidealização of the real child is important for the creation and strengthening of parental ties considered essential to the care and healthy development of the child.
\end{abstract}

Keywords: Child. Development. Idealization. Reidealizatio.

\section{IMPACTO DE LA ATENCIÓN PARA EL DESARROLLO SALUDABLE DE LOS NIÑOS EN LA NIÑEZ TEMPRANA}

Resumen: El presente artículo tiene por objeto compreender el impacto que el cuidado dispensado al niño em la primera infância tiene en su desarrollo, así como presentar el importante papel que la idealización y la reidealización tiene em lo que tange el cuidado necessário com el niño para seu desarrollo saludable. Se realizó mediante un enfoque cualitativo de revisión de literatura narrativa. Para ello, se hizo un análisis de aspectos señalados por la literatura como relevantes para el entendimiento del proceso de idealización y reidealización del niño real por los padres, según Franco $(2015,2016)$, Jerusalinsky $(2006,2010)$, Winnicot $(2005,2012)$, Bowlby (2002) y otros autores que tratan el tema. Se concluye que la capacidad de los padres de idealización y reidealización del hijo real es importante para la creación y fortalecimiento de los vínculos parentales considerados imprescindibles para el cuidado y desarrollo saludable del niño.

Palabra clave: Niño. Desarrollo. Idealización. Re-realización. 


\section{Introdução}

O ser humano é, por assim dizer, o ser mais precário ao nascer. No entanto, é o mais rico do ponto de vista das potencialidades que o constituem. Tais potenciais precisam de condições favoráveis para que sejam desenvolvidas; caso contrário, poderão sofrer atrofia.

É preciso, no entanto, compreender que as atitudes, as emoções e o tipo de interação que os pais estabelecem com o filho desde a vida intrauterina ficam registrados e se constituem em dados fundamentais para compreendermos o desenvolvimento psicossocial da criança. Quando queremos entender os motivos de determinados comportamentos e interações que ela estabelece com as pessoas à sua volta, não podemos descurar do modo como fora tratada. Isso vale para o entendimento não só das atitudes da criança, mas também para a compreensão acerca da vida subjetiva do adulto, uma vez que suas experiências sociais permanecem como matéria-prima para as suas respostas atitudinais ao longo da vida.

Este artigo tem por objetivo compreender o impacto que o cuidado dispensado à criança na primeira infância tem sobre o seu desenvolvimento, bem como apresentar o importante papel que a idealização e a reidealização têm no que tange ao cuidado necessário com a criança para o seu desenvolvimento saudável. Tendo presente que os primeiros anos da infância (0-5 anos) são considerados como decisivos na constituição do psiquismo do sujeito, busca-se ressaltar o indiscutível peso da influência das descobertas da psicanálise na formação dos profissionais que irão atuar junto à criança nessa etapa de vida. Uma vez que nesse período de vida a criança está experienciando o surgimento da sexualidade e os registros emocionais nesse caso incidem sobre o ego imaturo e frágil, gerando trauma (FREUD, 1927).

A escolha do tema se deu pela inquietação ao refletir sobre os desafios apresentados nas vivências no estágio de psicologia realizado na maternidade, justificando a relevância dos estudos no sentido de compreender o impacto que o cuidado dispensado pelos pais à criança na primeira infância tem sobre o seu desenvolvimento, bem como analisar e entender o papel da idealização e reidealização como condição de investimento na criança real. 
Para o desenvolvimento deste artigo, optou-se pela abordagem qualitativa de revisão de literatura narrativa. Para tanto, foi feita uma análise de aspectos apontados pela literatura como relevantes para o entendimento do processo de idealização e reidealização da criança real para a criação e fortalecimento dos vínculos parentais considerados imprescindíveis ao cuidado e desenvolvimento saudável da criança, segundo Freud (1927), Franco (2015, 2016), Jerusalinsky (2006), Winnicott (2012), Spitz (1998), Bowlby $(1990,2002)$ e outros autores que tratam do tema.

0 estudo está dividido em três partes: a primeira é direcionada à análise da importância do processo de idealização para o estabelecimento dos vínculos de parentalidade e cuidado da criança; a segunda parte aborda o processo de reidealização como um empreendimento necessário dos pais para o desenvolvimento saudável da criança. Já a terceira parte trata da análise da díade mãe/bebê, buscando mostrar a importância do papel desempenhado pela mãe no período gestacional e primeira infância. Cabe ressaltar que ao longo do texto buscou-se evidenciar a importância dos conhecimentos oriundos do campo da psicanálise para subsidiar a prática educativa dos profissionais que atuam na Educação infantil, a fim de influenciar positivamente a criação e educação das crianças, possibilitando o desenvolvimento de adultos mais saudáveis e felizes. Isto é, buscar um ponto ótimo de atuação dos pais e educadores junto á criança no intuito de possibilitar-lhes na sua atuação junto à criança atingir o máximo, com o mínimo de danos.

A fim de que possam efetivar os cuidados necessários e, consequentemente, prevenir o sofrimento melhorando as práticas educativas, bem como o atendimento e cuidados oferecidos à criança, considera-se fundamental a criação e fortalecimento dos laços parentais, bem como o esclarecimento dos pais ou responsáveis e educadores acerca dos mecanismos psíquicos sobre os quais se baseia o desenvolvimento psicossocial da criança,

\section{0 processo de idealização (parentalização)}

O nascimento não se configura como o primeiro momento de vida da criança, pois ela já existe intrauterinamente no ventre da mãe. Não obstante, o nascimento é um marco delimitador da entrada da criança na vida autônoma. Vale lembrar que, por conta 
da sua "precariedade" e fragilidade, a criança recém-nascida ainda terá de permanecer por um longo tempo dependente dos cuidados da mãe ou responsável para conseguir sobreviver e ganhar gradativamente autonomia (SPITZ, 1998; WINNICOTT, 2012).

Podemos dizer que a criança que é desejada e planejada pelo casal, sendo, mesmo antes de existir, já contemplada nos planos dos futuros pais, tem condições mais favoráveis à sua evolução psicológica saudável. Em contrapartida, a criança rejeitada, resultante de uma gravidez indesejada, sofre os impactos de todas as emoções negativas advindas das vivências subjetivas dos pais. Isso vale também para os casos de crianças que, ao nascer, são rejeitadas por não corresponderem às expectativas postas no imaginário dos pais (FRANCO, 2015).

Winnicott (2005) afirma que bebês que recebem cuidados e atenção tendem a apresentar um desenvolvimento saudável e aqueles que de alguma forma são tratados de modo inadequado, negligenciados em suas demandas, ou que sofrem maus tratos tendem a apresentar algum tipo de comportamento como, por exemplo: inquietude, apatia, inibição, dentre outros. 0 que reforça a ideia de que é extremamente importante que a criança tenha não só as necessidades físicas supridas, mas também afeto (JERUSALINSKY, 2010; WINNICOTT, 2012). Sendo assim, é importante que a mãe ou aquele(a) que exerce esse papel o faça de modo que a criança se sinta confortável e segura. A maternagem, no caso, é fundamental para conferir à criança um aporte de cuidados que the possibilitem dar início a um processo de desenvolvimento pessoal e real (FRANCO, 2015; BOWLBY, 1990; 2002; WINNICOTT, 2012).

Antes mesmo de nascer, o bebê já existe no imaginário dos pais (FRANCO, 2015; JERUSALINSKY, 2010). A idealização é apontada por Franco (2015) como sendo a condição de possibilidade de cuidado por parte dos pais. Jerusalinsky (2006) afirma que a fantasia da mãe, ou melhor, do casal parental, quanto à chegada do bebê se constitui como fator primordial que deixa registros fortes na criança e têm implicações na constituição do laço conjugal.

O lugar que será ocupado pelo filho dentro da casa e na vida do casal é estabelecido no processo de idealização realizado bem antes de o bebê nascer (FRANCO, 2009, 2015). Ele é engendrado no imaginário do casal quando ainda está na expectativa da vinda do filho, investindo psíquica e emocionalmente nesse. Portanto, podemos deduzir daí que é 
a idealização realizada no processo de parentalização que cria as condições físicas e psíquicas para o acolhimento necessário do bebê (FRANCO, 2009; JERUSALINSKY, 2006).

O bebê real que nasce é acolhido no discurso e desejo dos pais simbolicamente antes mesmo de existir fisicamente (FRANCO 2009, 2016; WINNICOTT, 2012). A relação parental se dá mediada por um corpo simbólico, isto é, por uma imagem projetada na criança real segundo os desejos e ideais dos pais, que investem afetivamente a partir do que esperam da criança. Segundo Franco (2015, p. 206): “é a idealização do filho imaginário que vai preparando a família para um bebê real que irá nascer”. Durante o período gestacional, os pais vão se tornando pais e idealizando o filho que desejam ter. É, pois, esse filho idealizado, que tem as melhores características dos pais e que realiza as fantasias e desejos deles, sendo ainda melhor que eles, que, para Franco (2015, p. 208): “dará substrato psíquico para a mãe entrar em relação como o bebê real”.

Não obstante, quando a idealização não ocorre, a criança real corre o risco de ser rejeitada, ignorada em suas demandas e necessidades básicas.

Quando esse pré-vínculo não se constrói, ou seja, os pais não conseguem imaginar os seus filhos, esses bebês incorrem no risco de abandono físico ou emocional, negligência ou falta de cuidados adequados. As crianças que não nasceram na imaginação dos seus pais são crianças sem um lugar para nascer, crescer e se desenvolver e, por isso, são crianças emocionalmente abandonadas (FRANCO, 2015, p. 208).

A idealização, no caso, é a condição sine qua non do apego dos pais à criança que está por vir e que, ao chegar ao mundo, encontra um lugar para nascer, uma vez que já existe no imaginário dos pais (FRANCO, 2015; JERUSALINSKY, 2006, 2010; WINNICOTT, 2005, 2012).

A notícia da chegada de um filho na família requer uma série de mudanças que mexem com o imaginário do casal. Essas modificações vão desde o planejamento quanto ao lugar que a criança irá ocupar na casa até os preparativos do enxoval. Isso equivale a dizer que, mesmo antes de nascer, o(a) filho(a) já ocupa um lugar importante na rotina e planejamento da família. Esse filho(a) imaginário já conta, por assim dizer, com investimento libidinal dos pais e, mais especificamente, da mãe (JERUSALINSKY, 2006). É justamente esse investimento que, nas diferentes abordagens da psicologia infantil, irá criar as condições para que o recém-nascido possa contar com o necessário apoio e 
amparo da mãe no que tange às suas demandas (FRANCO, 2009, 2015; WINNICOTT, 2012).

Quando ocorre de a criança apresentar algum tipo de deficiência, ou de algum modo não corresponder às expectativas dos pais, muito de todo o planejamento realizado até então perde a razão de ser (FRANCO, 2009, 2015). 0 que fora idealizado com relação à criança não serve mais, pois não há mais condições de ser realizado. Nos casos, por exemplo, do diagnóstico de síndrome de Down, a mãe sente-se insegura diante de uma notícia para a qual não se encontra preparada, tendo que elaborar a frustração de ver seus planos, projetos e sonhos desfeitos. Além disso, tem ainda que pensar nas mudanças de ordem física, psicológica e social que terá de enfrentar. Tudo isso gera nela sentimentos ambivalentes. O luto é consequência, isto é, uma reação relacionada à perda do filho imaginário (FRANCO, 2009, 2015, 2016; JERUSALINSKY, 2010).

0 trabalho do luto resulta no desinvestimento libidinal no(a) filho(a), uma vez que ele não existe mais. As expectativas são rompidas no momento do anúncio do diagnóstico (JERUSALINSKY, 2010). Sendo assim, pode ocorrer de a mãe enlutada não conseguir fazer o investimento libidinal no(a) filho(a) real, negando-lhe, por assim dizer, os cuidados e afetos de que necessita no momento para que possa se sentir amparado(a) e seguro(a) (BOWLBY, 1990, 2002; WINNICOTT, 2012). Dito de outro modo, nesse momento a mãe não consegue ser "continente" para o(a) filho(a), isto é, não consegue desempenhar a importante função que lhe é atribuída de "holding" enquanto "mãe suficientemente boa” (WINNICOTT, 2012).

\section{0 processo de reidealização}

0 período que corresponde à gravidez é habitualmente associado ao conjunto de expectativas vividas pelos pais. Nele prepondera uma série de esperanças, de sonhos e de fantasias elaborados de modo consciente ou não em relação ao novo ser que está chegando à vida do casal. Ocorre na gestação a identificação do bebê especialmente com a mãe. A criança em formação, embora ainda desconhecida, já encontra ressonância na mãe que constrói sua imagem a partir dela mesma. Ainda no útero, o bebê já pode constituir uma imagem psíquica, sexuada, que tem um nome. Sendo assim, ele já existe no imaginário dos pais relacionado ao desejo de terem um(a) filho(a) (FRANCO, 2009; 
WINNICOTT, 2012). Dito de outro modo, o primeiro vínculo dos pais com o bebê se forma bem antes de ele vir ao mundo. Sendo assim, podemos dizer que o bebê imaginado pelos pais no período gestacional é parte deles mesmos, enquanto construção deles (FRANCO, 2009, 2015; WINNICOTT, 2012). Na perspectiva de Franco $(2009,2015)$, o desejo dos pais é considerado fundamental para a construção do bebê idealizado. São esses desejos que possibilitam a vinculação da mãe com o bebê que está por vir ao mundo. 0 bebê ideal incorpora semelhanças físicas com os pais, dando vazão ao narcisismo desses, que veem no(a) filho(a) aspectos de si mesmos que consideram relevantes. Há aí nessa imagem idealizada do bebê a criação da possibilidade de libidinização do corpo enquanto ser separado, no qual os pais irão investir libidinalmente.

Pode-se dizer que inicialmente a criança se encontra num estado de não integração mediante o qual a integração vai ocorrendo gradativamente até que se efetive de fato. $A$ integração depende do "holding”, ou seja, do cuidado que the é dispensado no ambiente em que se encontra. A imagem mais próxima que ilustra a função desse cuidado é a da forma como a mãe segura o bebê em seus braços (WINNICOTT, 2012). A falta desses cuidados leva a criança a experienciar um alto nível de tensão e ansiedade. No sentido oposto, o cuidado de sustentação tem o poder de transformar essas ansiedades em experiências positivas.

À medida em que o tempo passa, o self da criança vai sendo construído, ela então vai tornando-se capaz de incorporar as lembranças do cuidado ambiental bem como do cuidado de si mesmo. Sendo assim a criança que goza de cuidados vai se sentindo mais segura e confiante. No caso de bebês que por motivos diversos não se sentem seguros eles se tornam crianças ansiosas, agitadas, que não conseguem relaxar, a não ser quando já exaustos.

Caso não ocorra a idealização do filho que o pré-vincula aos pais, ele corre o risco de sofrer abandono físico, emocional, sendo maltratado ou negligenciado nos cuidados necessários ao seu desenvolvimento normal. Segundo Franco (2015), as crianças precisam ser desejadas no imaginário dos pais para que possam ter um lugar para nascer. Quando a mãe tem uma capacidade limitada de holding, não raro a criança adoece como uma forma de tentar obter o holding por meio dos cuidados requeridos pelo adoecimento. No caso, a doença funciona como um expediente para alcançar o cuidado necessário 
(WINNICOTT, 2012). Muitas vezes crianças acolhidas de modo rude e sem afeto acabam falecendo precocemente, definham, perdem o interesse pela vida. Winnicott (2012), Franco $(2009,2015)$ salientam em seus escritos que o olhar da mãe confere ao bebê existência. 0 rosto da mãe é, nesse sentido, o precursor do espelho. Segundo esses autores, a criança encontra no olhar da mãe e dos familiares ou cuidadores através dos cuidados dispensados a ela o seu lugar de pertencimento a partir do qual estabelecerá trocas significativas com o mundo como lugar seguro (BOWLBY, 2002).

No caso das crianças que quebram as expectativas dos pais no que tange ao/à filho(a) idealizado(a), elas necessitam dar conta das reverberações que essa situação provoca no seu mundo mental, emocional e social. A frustração causada pela constatação de alguma anomalia ou deficiência na criança põe em xeque as projeções que os pais abrigaram acerca do(a) filho(a) e isso abala as representações simbólicas que eles alimentaram por muito tempo quando da espera pela chegada do bebê. A criança real não corresponde ao/à filho(a) imaginado(a), idealizado(a) pelos pais. No entanto, ela é real e carece de cuidados e de investimento libidinal. Quando a mãe tem uma capacidade limitada de holding, não raro a criança adoece como uma forma de tentar obter o holding por meio dos cuidados requeridos pelo adoecimento. No caso, a doença funciona como um expediente para alcançar o cuidado necessário (WINNICOTT, 2012). Muitas vezes crianças acolhidas de modo rude e sem afeto acabam falecendo precocemente, definham, perdem o interesse pela vida. Winnicott (2012), Franco (2009, 2015) salientam em seus escritos que o olhar da mãe confere ao bebê existência. 0 rosto da mãe é, nesse sentido, o precursor do espelho. Segundo esses autores, a criança encontra no olhar da mãe e dos familiares ou cuidadores através dos cuidados dispensados à ela o seu lugar de pertencimento a partir do qual estabelecerá trocas significativas com o mundo como lugar seguro (BOWLBY, 2002).

Nesse sentido o autor salienta que:

Se a premissa que todas as crianças nascem primeiro na idealização dos pais, e, mais do que isso, é essa idealização que lhes dá possibilidade de existirem e serem cuidadas, a questão nuclear no desenvolvimento desses pais e da criança não é o luto, mas o que the segue. Se o que foi idealizado não nasceu, pois era o "outro", há agora uma criança a ser cuidada e investida emocionalmente como filha (FRANCO, 2015, p. 214). 
Partindo do pressuposto de que o processo de idealização realizado pelos pais é considerado a condição da possibilidade de acolhimento e cuidado, no momento em que ocorre a ruptura do idealizado frente ao real, há necessidade de uma reelaboração das representações simbólicas a fim de que as condições de acolhimento e cuidado para o desenvolvimento do bebê sejam postas novamente (JERUSALINSKY, 2006).

Segundo Franco $(2015,2016)$, a criança real precisa ser reidealizada pelos pais a fim de que eles possam investir emocionalmente no sentido de criar e fortalecer os laços considerados imprescindíveis ao desenvolvimento dela. Isso significa mais do que o cumprimento de obrigações protocolares, funcionais, de tarefas consideradas necessárias à manutenção da vida da criança.

A reidealização pressupõe o envolvimento emocional dos pais, a criação de vínculos de parentalidade que possibilitem ao bebê real o desenvolvimento considerado fundamental para toda e qualquer criança. “A reidealização implica um segundo nascimento da criança. Ao invés do que acontece habitualmente, o nascimento que se deu primeiro na realidade e depois na imaginação dos pais” (FRANCO, 2015, p. 215).

A reidealização é considerada, portanto, o que possibilita a retomada do processo de desenvolvimento da relação dos pais com o(a) filho(a). A partir dela há um reinvestimento na criança real, dentro das suas condições reais. Isso equivale a dizer que ela é a condição para que ocorra o investimento libidinal dos pais no(a) filho(a) como ele(a) é e pode ser, e não como poderia ter sido (FRANCO, 2015, 2016).

Vários teóricos reiteram que a infância é uma das fases mais importante do desenvolvimento humano. Nela a criança necessita de cuidado e atenção constantes a fim de que sejam supridas suas necessidades fisiológicas e emocionais e se sinta segura e amparada para explorar e conhecer o mundo no qual se encontra inserida. Nesse sentido, o afeto torna-se ingrediente fundamental para o desenvolvimento saudável da criança.

Sendo assim, reitera-se a necessidade de os pais serem presentes na vida da criança, estabelecendo um vínculo emocional que dê a ela segurança e confiança (WINNICOTT, 2012; BOWLBY, 1990, 2002). Para tanto, é importante que os pais estejam atentos ao fato de que a criança precisa mais do que tão somente ter suas necessidades fisiológicas atendidas, ela carece de afeto, acolhimento e amparo. A criação de um filho 
requer, portanto, um trabalho conjunto de afeto, acolhimento, presença e equilíbrio de todos aqueles que estão implicados com a vida dessa criança, em especial da mãe. Segundo Winnicott (2012), a mãe suficientemente boa é aquela que acolhe e ampara o filho com os cuidados necessários à sua sobrevivência física e emocional.

Nesse sentido, vale ressaltar o papel que os educadores desempenham junto à criança e, não obstante, à família. 0 olhar atento dos educadores no modo como a criança brinca, do que brinca e como expressa suas fantasias principalmente no que tange aos significados dos conteúdos e seus possíveis traumas, confere-lhe um papel muito importante para o desenvolvimento saudável da criança e para a orientação dos pais e familiares para o desempenho de suas atribuições parentais. Através do brincar o educador pode obter informações importantes acerca das experiências simbólicas dos seus conflitos internos. Enquanto o adulto verbaliza através da fala seus conflitos, a criança o faz através do brincar. Para Winnicott (2005) criança e ambiente estão interligados. Todo ser humano pode desenvolver seus potenciais de modo saudável, desde que o ambiente em que vive seja propício.

A criança real nem sempre corresponde ao filho idealizado pelos pais. Essa constatação leva-os a ter de gerenciar o conflito que traz à tona o impasse vivido por eles, que terão de superar o desafio posto pelo filho real no contraponto com o filho idealizado. Dito de outro modo, a quebra de expectativas, causada pelo nascimento do bebê real, constitui-se como restrição do desejo de plenitude narcísica dos pais (FRANCO, 2009, 2015, 2016; JERUSALINSKY, 2010).

Há casos em que ocorre um desenvestimento muito acentuado por parte dos pais, o que deixa vácuos psíquicos que terão de serem preenchidos pelo reinvestimento dos pais ou daqueles que cercam a criança. Os educadores da Educação Infantil muitas vezes terão essa incumbência de reinvestir na criança já que o desenvestimento central do objeto primordial (mãe) por algum motivo não foi possível de ser realizado. A criança então apresenta sinais em seu comportamento e atitudes da violência que experenciou cabendo ao profissional ao qual está sob os cuidados o papel de impulsioná-la positivamente e orientar os pais e familiares quanto as demandas da criança.

A perda do filho idealizado terá de ser elaborada pelos pais, a fim que o filho real, com suas limitações e possibilidades de desenvolvimento, possa, efetivamente, nascer 
uma segunda vez, agora de forma significativa no universo simbólico dos pais, através de um reinvestimento por meio de novas representações e idealizações que tenham como base a criança real como ela é, e não mais como gostariam que fosse(FRANCO, 2009, 2015, 2016).

\section{Díade mãe-bebê}

No momento do nascimento, ao vir ao mundo, o bebê não é uma "tábula rasa". Ele traz o registro das experiências intrauterinas. Ainda no ventre da mãe, a criança sofre influência do meio, tem percepção do mundo, constituindo-se como parceira na relação com os pais. 0 modo como esses vivenciam a gravidez, bem como a forma de nascimento, têm influência sobre o desenvolvimento psicológico da criança. 0 desejo dos pais com relação ao filho e as emoções da mãe são comunicados à criança e essa, por sua vez, levará consigo o registro dessas experiências (FRANCO, 2015).

Cabe salientar, no entanto, que há entre a mãe e a criança uma relação de interferência mútua no período gestacional. As emoções da mãe afetam a criança, provocando mudanças fisiológicas. 0 organismo da mãe também sofre alterações como resposta às condições de, por exemplo, temperatura e oxigenação da criança. 0 modo de pensar, sentir e agir dos pais "grávidos" criam determinadas condições para o desenvolvimento saudável ou não da criança na fase intrauterina. 0 desejo, investimento libidinal, na espera e recepção da criança no nascimento influenciam diretamente a qualidade dos mesmos (JERUSALINSKY, 2010).

A psicanálise tem mostrado que até mesmo a vida intrauterina do bebê é rica em termos de registros emocionais. Nesse sentido, o nascimento é visto como sendo um evento importante, que tem significado para a criança. Para Winnicott (2005), no momento do nascimento, a mãe é considerada a pessoa mais indicada para apresentar o mundo ao bebê, por nenhuma outra razão que não seja a de ser ela a mãe natural.

Não obstante, é preciso que ela esteja bem e saudável para que possa exercer o seu legítimo papel de mãe. Segundo o autor, se a mulher for coagida, sofrer violência, não for devidamente contemplada em sua subjetividade, condição física e psicológica, seus recursos naturais, isto é, seus instintos sofrerão mudanças, comprometendo a sua condição de cuidado com o bebê (BRASIL, 2011). 
Winnicott (2005) salienta que, após o nascimento do filho, dependendo de como o parto foi realizado, a mãe pode se apresentar extremamente cansada, extenuada pelo trabalho de parto e por possíveis complicações decorrentes desse. No entanto, mesmo precisando do auxílio dos profissionais que fizeram o parto, a seu ver, ela continua sendo, ao mesmo tempo, a especialista no que diz respeito à amamentação e cuidados relativos ao bebê. Segundo o autor, alguns profissionais da saúde têm dificuldade em admitir essa ambivalência da puérpera e tratam-na como incapaz de dar conta do seu papel de mãe.

0 parto natural, sem violência obstétrica, por si só já traz em si mesmo uma experiência traumática para a criança, que, num curto espaço de tempo, sai de condições favoráveis no ventre e se encontra exposta a estímulos externos um tanto desagradáveis. A percepção dos pais com relação às dificuldades de adaptação da criança à realidade fora do ambiente uterino é fundamental para ajudá-la nessa habituação (WINNICOTT, 2005). Ao proteger o recém-nascido de todo e qualquer estímulo exterior excessivo que gere desconforto, os pais estão numa relação de parceria fundamental para o desenvolvimento psicológico saudável dele.

0 recém-nascido encontra-se em relação com a mãe como que fusionado com ela, ainda não se percebe como um indivíduo. Essa unidade dual mãe-bebê perdura até por volta dos dois meses e é chamada de fase simbiótica normal. Nesse momento, até a criança evoluir da fusão à identidade, ela carece do olhar e cuidados da mãe (WINNICOTT, 2005).

O comportamento de sustentação (holding) da mãe é considerado essencial para a criança se sentir segura e poder se desenvolver bem. Winnicott (2005); Spitz (1998) ressaltam que a maternagem, o contato caloroso, ou seja, os cuidados dispensados pela mãe ao bebê são fundamentais para que ele possa estabelecer contatos afetivos saudáveis. Essa relação com a mãe é crucial para o desenvolvimento psicológico da criança, uma vez que forma a base mediante a qual ela estabelecerá suas relações sociais ao longo da vida.

Segundo Franco (2015), já no final da gravidez instaura-se na mãe um estado de hipersensibilidade. Winnicott (2005) refere-se a esse estado denominando-o como “preocupação maternal primária”. Essa condição de hipersensibilidade não se restringe 
somente ao final da gravidez, pois perpassa de forma gradual crescente todo o período gestacional da mulher, permanecendo durante algumas semanas após o parto.

A mãe é como que preparada biologicamente, isto é, naturalmente, a suprir as demandas iniciais da criança durante as primeiras semanas de vida, conferindo-lhe uma espécie de suporte seguro à existência, uma vez que a condição do bebê é de extrema fragilidade e requer cuidados especiais (WINNICOTT, 2012).

Cabe ressaltar, no entanto, que a mãe terá condições de exercer bem esse papel, cumprindo sua função, se tiver experienciado relações de amor, cuidado, segurança, entre outras. 0 desenvolvimento da criança no decorrer dos primeiros meses de vida encontra-se intimamente vinculado aos cuidados maternais de uma "mãe suficientemente boa" (WINNICOTT, 2005), capaz de adaptar-se às necessidades da criança na fase de sustentação que compreende os primeiros seis meses de vida. Nesse caso, o autor diz que o “ego da mãe está em harmonia com o ego do filho [...] é esta criança, cujo ego é forte devido ao apoio do ego na mãe, que cedo torna-se verdadeiramente ele mesmo ou ela mesma" (WINNICOTT, 2005, p. 24).

Essa é a denominada "fase de sustentação". Ela é caracterizada pela necessidade de a mãe "sustentar" a criança com seus cuidados e atenção (WINNICOTT, 2012). A mãe, no caso, não só carrega e protege fisicamente a criança, mas também busca dar conta das suas mudanças físicas e psicológicas no decorrer dos dias.

Sendo assim, na díade mãe/bebê, a mãe assume um papel importante no sentido de suprir as necessidades físicas e psicológicas do filho, cabendo-lhe cumprir as funções de apoio quando necessário. Winnicott (2005) salienta a necessidade de identificação da mãe com o seu bebê. A partir dessa identificação, ela está em condições de exercer as funções de proteção, cuidado (físico, psicológico) e de segurança do filho (FRANCO, 2015; NASIO, 1995; WINNICOTT, 2012). A “mãe suficientemente boa” é aquela que não deixa o filho por um tempo superior àquele que ele é capaz, dentro das suas condições, de acreditar na sua existência e não se sentir desamparado, abandonado (NASIO, 1995).

Tais funções são descritas como: Holding, Handling e apresentação de objetos. Segundo Winnicott (2012), se o Holding for satisfatório, a criança experimentará a satisfação de uma porção básica de cuidado. Caso contrário, se o Holding for deficiente, ela experimentará a aflição e frustração que a levará a perceber o mundo externo como 
algo que gera desconforto. Como podemos observar do que foi dito, o ambiente favorável possibilita o desenvolvimento saudável da criança, permitindo a ela ir gradativamente saindo da dependência absoluta para uma dependência relativa.

Como é possível observar, nessa fase de desenvolvimento, a criança vai pouco a pouco se percebendo como pessoa e estabelecendo relações diferenciadas com o outro e com o meio ambiente. Nesse processo de crescimento e maturação, o desempenho do papel da mãe enquanto "mãe suficientemente boa” é crucial para o desenvolvimento sadio da criança (FRANCO, 2015; WINNICOTT, 2012).

No processo de maturação, após a "fase de sustentação", segundo Winnicott (2012), a criança experimenta graus de independência da mãe que variam da dependência absoluta, passando pela etapa de independência relativa e, por fim, alcançando a independência. Cada uma dessas três etapas requer cuidados maternais que já vinham sendo necessários na “fase de sustentação" mencionada e que compreende os processos de integração, personalização e realização da criança.

Cabe ressaltar, no entanto, que os cuidados dispensados pela mãe à criança precisam vir acompanhados de doses de afeto e atenção para que essa se sinta acolhida e segura. A "mãe funcional”, que cumpre as tarefas de modo protocolar quanto aos cuidados direcionados ao filho, segundo Franco (2015), priva-o do seu afeto, podendo gerar com esse comportamento danos ao desenvolvimento e maturação da criança (WINNICOTT, 2012; BOWLBY, 2002).

Nasio (1995) salienta que a criança privada do cuidado da mãe na fase de dependência absoluta (de zero a seis meses) tenderá a sentir uma angústia ameaçadora de aniquilação, que poderá chegar à mutilação da capacidade de estabelecer relações com outras pessoas. 0 autor explica que as consequências da falta de cuidado e privação da figura materna variam conforme a fase de desenvolvimento em que a criança se encontra quando da experiência de privação.

Para Spitz (1998), a relação mãe/criança sofre mudanças consideráveis ao longo do primeiro ano de vida. A criança recém-nascida não diferencia o eu do não eu. Segundo o autor, ao longo desse período, ela vai pouco a pouco se diferenciando da mãe e, por volta de um ano, é que conseguirá estabelecer a relação objetal. Porém, vale ressaltar 
que aos três meses a criança já distingue o eu do não eu, ou seja, consegue discernir o que sente no interior daquilo que vê no exterior.

Conforme o exposto, nos primeiros três anos de vida, mais especificamente no primeiro ano, a relação da criança com a mãe é fundamental para o seu desenvolvimento saudável. Caso essa relação seja obliterada ou não satisfatória e a função materna não seja exercida por outra pessoa, a criança correrá sérios riscos de adoecer, entrar em depressão e, consequentemente, apresentar um comprometimento com relação à locomoção, alimentação, higiene corporal e linguagem, podendo agravar-se e ir a óbito (FRANCO, 2015; JERUSALINSKY, 2006; SPITZ, 1998; WINNICOTT, 2005).

Nesse sentido, Bowlby (2002) ressalta outros sintomas da negligência e carência afetiva na criança nos primeiros anos de vida, quais sejam: ansiedade alta, desejo de vingança, instabilidade emocional e dificuldade de desenvolvimento. Em contrapartida, Winnicott (2005), por exemplo, afirma que, quando acompanhada de afeto, a mamadeira pode ser um substituto do seio materno sem prejuízo para a criança. 0 que equivale a dizer que não é necessariamente o que se faz, mas a qualidade afetiva das ações realizadas por ela que suprem as demandas afetivas da criança.

Fica evidente no seu comportamento a repercussão do modo de tratamento que a criança recebeu dos pais, ou seja, na qualidade dos vínculos estabelecidos e dos mecanismos de apaziguamento, de agressão ou ameaça utilizados por ela na interação com o meio em que se encontra inserida. Sua afirmação como pessoa depende em grande parte dessas interações (BOWLBY, 1990).

O processo gradual de independização da criança, a evolução da fusão com a mãe para a autonomia, quando bem assistido, possibilita que a criança desenvolva uma boa autoestima e sinta prazer em agir de modo autônomo, uma vez que se sente segura (BOWLBY, 2002).

Num ambiente hostil, onde a criança não tem suas necessidades básicas e de afeto supridas, o processo de socialização se dará de forma deficitária. A mãe desempenha importante papel no processo de individuação e interação social da criança. É ela que, com suas atitudes, irá dar à criança a segurança necessária para explorar o mundo que a rodeia (BOWLBY, 2002). 
Na prática, os bebês sujeitos a maus tratos ou negligência passam a evitar prestar atenção aos interlocutores que expressam qualquer tipo de emoção. Obviamente, a médio e longo prazo, tal comportamento pode afetar suas relações e interações com outras pessoas e até mesmo levar a criança a desenvolver ansiedade e depressão. Para evitar o desconforto gerado pela negligência ou maus tratos, o cérebro do bebê é como que "desconectado". Assim ele evita o desconforto demasiado (NASIO, 1995; WINNICOTT, 2012).

A criança usa estratégias para evitar situações que são altamente ansiogênicas ou temidas. Na verdade, ela lança mão de um mecanismo básico de defesa, a "evitação". Dessa forma ela busca proteção. Quando não é possível escapar de determinadas situações, o cérebro tende a "desconectar-se", a fim de poder suportar o desconforto. No entanto, quando nos primeiros meses o bebê se encontra em tal situação, seu cérebro sofrerá alterações e ele não conseguirá processar de modo adequado as informações emocionais (NASIO, 1995; WINNICOTT, 2012).

Crianças que são vítimas de negligência e maus tratos constantes apresentam um comportamento evitativo. A fim de não sentirem o desconforto que as expressões emocionais de raiva, nojo ou desconforto dos pais lhes causam, a criança evita manter contato com tais emoções e, muitas vezes, nega-as (WINNICOTT, 2012; BOWLBY, 2002).

Desse modo, para anular os sentimentos aversivos gerados pelo comportamento dos pais para com ela, a criança sofre como por assim dizer uma mutilação do sistema de processamento das emoções, tornando-a incapaz de perceber as expressões emocionais positivas de outras pessoas que interagem com ela. De fato, o impacto no nível cerebral da negligência e maus tratos em crianças na primeira infância danifica o cérebro e compromete o seu equilíbrio emocional (NASIO, 1995).

Os pais sempre precisam estar atentos às demandas da criança, mas o período que vai do nascimento aos 12-18 meses, segundo vários teóricos, requer uma atenção especial. Nessa fase do desenvolvimento psicossocial da criança, ela elabora a percepção de se o mundo é seguro ou não. Para Bowlby (2002), a expressão "privação da mãe" corresponde à situação em que a criança se encontra parcial ou totalmente privada da figura que lhe dispensa a atenção necessária às suas demandas. 
Entender as fases de desenvolvimento psicossocial da criança, bem como as características próprias de cada fase, possibilita aos pais lidarem com sabedoria para com os seus filhos de modo a proporcionarem a eles condições favoráveis ao desenvolvimento saudável.

Nesse sentido, é importante que os pais saibam reconhecer que a criança está com medo e dar-lhe a devida atenção, acolhendo-a e respeitando-a na sua condição de temor. Até por volta dos seis meses de idade, a criança apresenta medo de barulho forte, ruídos intensos e altos e, também, de perda do contato físico com a mãe. Nesse caso a criança se sente insegura. A mãe, no caso, é quem lhe dará as condições necessárias para sentirse segura (WINNICOTT, 2012).

Dos sete aos doze meses, outros medos passam a ser evidenciados no comportamento infantil. Podemos destacar o medo de desconhecidos e de que os pais, ao se ausentarem, desapareçam, deixando-os desamparados. Esse tipo de medo costuma se estender até por volta dos três anos de idade. Sendo assim, é necessário que os pais saibam lidar com a criança de modo a transmitir-lhe confiança e segurança nesses momentos em que ela se sente ameaçada, dando-lhe apoio para elaborar tais sensações que lhe causam sofrimento (WINNICOTT, 2012).

Em cada etapa de vida, a criança necessita de cuidado e atenção dos pais, que são para ela a referência de segurança (BOWLBY, 2002; SPITZ, 1998; WINNICOTT, 2012). 0 vínculo mãe-bebê é de suma importância para o bom desenvolvimento cognitivo e emocional da criança nos primeiros meses e anos de vida. Para Bowlby (2002), a primeira infância é considerada uma etapa de vida em que a criança carece de uma atenção redobrada dos pais, uma vez que falhas nesse período podem acarretar sérios problemas no seu desenvolvimento cognitivo e emocional. Dito de outro modo, nesse período a criança precisa se sentir segura, amada e protegida, isto é, cuidada.

0 vínculo afetivo vivenciado nesse período e no seguinte servirá de base para a fase da adolescência. Toda falta de cuidado e afeto dos pais nesse período crítico de desenvolvimento da criança terá consequências danosas para a integridade emocional do filho na sua trajetória de vida (NASIO, 1995).

Sendo assim, podemos dizer que amor, cuidado, atenção para com as necessidades e demandas da criança são, portanto, os pressupostos que contribuem para ela crescer 
com o apoio de que necessita e pouco a pouco ir autonomizando-se e, consequentemente, deixando de depender tanto dos pais. Muitas e controvertidas são as opiniões acerca de como os pais e, mais precisamente, a mãe devem educar o filho. Algumas pessoas entendem que carinho e atenção podem "estragar” a criança. Elas preconizam austeridade, rigidez no trato com o infante, como forma de não mimá-lo, ensinando-o, assim, a lidar com o mundo que a cerca de forma realística.

Crianças tratadas de modo rude, sem os devidos cuidados, negligenciadas em suas demandas, desrespeitadas nas suas singularidades e sensibilidade aprendem que não são merecedoras de cuidado e carinho, desenvolvendo uma baixa autoestima que repercutirá, sem sombra de dúvidas, nas suas relações, podendo vir a buscar relacionamentos tóxicos, abusivos (BOWLBY, 2002; NASIO, 1995; WINNICOTT, 2012).

Podemos dizer que, entre os diferentes teóricos do desenvolvimento infantil, é consenso que a primeira infância, ou seja, os primeiros anos de vida da criança (considerando gestação, parto, primeiros anos de vida de 0-3 anos) são fundamentais para o desenvolvimento nas diferentes dimensões do seu ser, tais como: física, emocional, cognitiva e cultural. Desde o período intrauterino e ao longo dos três primeiros anos de vida, designados primeira infância, a criança sofre o impacto no seu desenvolvimento tanto do meio circundante quanto das relações que os adultos estabelecem com ela.

\section{Considerações finais}

Como se pode depreender do exposto, a família é a mediadora da criança com o meio ambiente e pode se configurar como um fator de risco para o desenvolvimento dela. O predomínio de aspectos saudáveis ou patológicos, tanto do pai quanto da mãe, interfere no vínculo emocional que será estabelecido entre eles e a criança, podendo não obstante, deixar sequelas e comprometer o desenvolvimento saudável da criança.

0 investimento libidinal dos pais na criança ocorre bem antes do seu nascimento mediante o processo de idealização e continua após, no de reidealização frente ao filho real. Esses dois processos são considerados extremamente necessários para a criação e fortalecimentos dos vínculos entre a criança e os pais. Eles constituem a base para o estabelecimento do cuidado dos pais para com a criança e, consequentemente, para a 
criação das condições necessárias ao atendimento das demandas dessa, a fim de que possa se desenvolver de modo saudável.

A forma como a díade mãe-bebê se estabelece nos primeiros anos de vida deixa marcas profundas no indivíduo. A atenção ou negligência nos cuidados dispensados à criança influenciam o modo de apego que irá ser desenvolvido, tendo um impacto na imagem que ela formará de si mesma e na sua autoestima, interferindo na atitude que assumirá diante da vida.

Tudo parece indicar que as consequências da negligência ou maus tratos nos primeiros meses de vida, bem como do afeto não se limitam ao psicológico, mas também alteram a parte neurofisiológica e afetam áreas do cérebro responsáveis por processar estados emocionais da criança.

Sendo assim, os pais são para a criança a referência de cuidado e segurança. Eles servem de modelo para os filhos. A criança, no caso, desenvolve a percepção de si a partir do modo como é tratada pelos pais e, em especial, pela mãe. Quando privada da figura de cuidado materna, isto é, quando destituída dos cuidados maternos, "maternagem”, a criança experimenta uma angústia ameaçadora de aniquilamento que pode levá-la ao comprometimento do seu desenvolvimento saudável.

O modo como a criança experiencia o mundo nos primeiros anos de vida irá afetar consideravelmente a sua percepção acerca dele, ou seja, irá permitir desenvolver confiança e segurança ou insegurança em relação ao mundo. Lidar de modo amoroso, estabelecendo um vínculo em que o filho se sinta protegido, seguro e amparado nas suas necessidades e demandas de diferentes ordens é fundamental para o seu desenvolvimento saudável. Ao contrário, negligenciar as demandas próprias da criança nas diferentes fases de crescimento constitui-se como uma falha dos pais que, conforme for o seu grau, terá repercussões danosas para o desenvolvimento psicossocial e, até, dependendo do caso, físico da criança.

Vários teóricos reiteram que a infância é uma das fases mais importantes do desenvolvimento humano. Nela a criança necessita de cuidado e atenção constantes a fim de que sejam supridas suas necessidades fisiológicas e emocionais e se sinta segura e amparada para explorar o mundo no qual se encontra inserida. Nesse sentido, o afeto torna-se ingrediente fundamental para o desenvolvimento saudável da criança. 
Os pais precisam empreender esforços para não simplesmente aceitarem a criança dentro das suas condições, tornando-se meramente "funcionais", "protocolares". A criança real necessita para o seu desenvolvimento efetivo mais do que somente os cuidados necessários para a sua sobrevivência. Ela requer um lugar de nascimento nas representações simbólicas dentro do mundo psíquico dos pais.

Esse lugar de nascimento é produzido mediante a reidealização, que possibilita a volta do investimento libidinal dos pais na criança real. Tal processo não poderá ser feito tomando como modelo norteador a idealização realizada pelos pais quando ainda não haviam tomado consciência das limitações do filho.

0 processo de reidealização, no caso, pode ser entendido como um segundo nascimento da criança, que fora idealizada no período gestacional. A diferença é a de que agora é a criança real que nascerá na subjetividade dos pais, possibilitando a criação e fortalecimento dos vínculos entre eles e, consequentemente, o desenvolvimento da criança real dentro das suas condições reais. Sendo assim, os estudos apontam para a importância do cuidado na primeira infância para o desenvolvimento saudável do ser humano. Os conhecimentos oriundos da Psicanálise no que diz respeito aos bebês e as crianças pequenas sobre o desenvolvimento em seus aspectos psicoafetivos, sobre a importância das relações estabelecidas por elas com os adultos significativos, denominados primordiais, com os quais interagem e que se ocupam dos seus cuidados e demandas, são de suma importância para a atuação não só dos pais e familiares, mas também dos educadores que atuam junto à criança.

\section{Referências}

BRASIL. Ministério da Saúde. Portaria no 1.459, de 24 de junho de 2011. Dispõe sobre a Rede Cegonha no âmbito do Sistema Único de Saúde. Brasília: MS, 2011.

BOWLBY, J. Apego. São Paulo: Martins Fontes, 1990.

BOWLBY, J. Cuidados maternos e saúde mental. 4. ed. São Paulo: Martins Fontes, 2002.

FRANCO, V. A adaptação das famílias de crianças com perturbações graves do desenvolvimento - contribuição para um modelo conceptual. Infad-International Journal of Developmental and Educational Psychology, v. XXI, n. 1-2, p. 25-37, 2009.

FRANCO, V. Paixão-dor-paixão: pathos, luto e melancolia no nascimento da criança com deficiência. Rev. Latinoam. Psicopat. Fund., São Paulo, v. 18, n. 2, p. 204-220, jun. 2015. 
FRANCO, V. Tornar-se pai/mãe de uma criança com transtornos graves do desenvolvimento. Educ. rev., Curitiba, n. 59, p. 35-48, mar. 2016.

FREUD, S. Obras Completas. Madrid. Biblioteca Nueva, 1927-1933a p. 341-343 pt.:El porvenier de uma ilusión.

JERUSALINSKY, J. Temporalidade e desenvolvimento. In: JERUSALINSKY, J. Enquanto o futuro não vem: a psicanálise na clínica interdisciplinar com bebês. Salvador: Ágalma, 2006. p. 79-95.

JERUSALINSKY, J. A direção da cura que não se cura. In: JERUSALINSKY, A. Psicanálise e desenvolvimento infantil: um enfoque transdisciplinar. 5. ed. Porto Alegre: Artes e Ofícios, 2010. p. 89-106.

NASIO, J. D. Introdução às obras de Freud, Ferenczi, Groddeck, Klein, Winnicott, Dolto, Lacan. Rio de Janeiro: Zahar, 1995.

SPITZ, R. O primeiro ano de vida. São Paulo: Martins Fontes, 1998.

WINNICOTT, D. A família e o desenvolvimento individual. São Paulo: Martins Fontes, 2005.

WINNICOTT, D. Os bebês e suas mães. São Paulo: Martins Fontes, 2012

Recebido em: 12 abr. 2020

Aceite em: 05 jul. 2020 